\title{
FLAME IR THERMOGRAPHY USED FOR COMBUSTION RESEARCH AND TESTING OF FUEL OIL
}

\author{
by Victor V. Ghia
}

\begin{abstract}
Polytechnic University of Bucharest, Dep. Thermo-mechanical Equipments,
\end{abstract} Romania,

\begin{abstract}
Infrared thermography (ITH) new application in miniaturized combustion process research has developed an original method for combustion testing of fuel oil droplets, using a simulator The thermal power variation of radiation heat exchange, between the simulator combustion chamber wall and the burning droplet together with sooting high, were estimated. By research and the measurement of apparent temperature $\left(T_{a}\right)$ from droplet flame infrared thermograms (IRT), obtained new criteria for gas oil combustion quality determination. A complex graphologyc thermographyc method resulted, for research and testing of fuel oil droplet combustion, with advantageous industrial applications. As example, combustion with additived air (CWAA) of heavy fuel oil (HFO) at boilers, will be detailed.
\end{abstract}

\section{Introduction}

Combustion testing of fuel oil droplets is especially important for economic establishment of fuel oil quality as well as for advantageous improvement of combustion technologies. Infrared Thermography offers these possibilities using the accumulated experience by very efficient applications of fuel oil droplet combustion graphology, which develops a new branch of combustion science [1]. Similar, we can create and develop the droplet combustion thermography, which at first of all is used for droplet fuel oil flame analysis at miniaturized combustion testing. In addition valuable new data on combustion process intensification are obtained according to the apparent temperature $T_{a}$ variation presented in IRT [2] of burning fuel droplet flame. CWAA of HFO, improved using the method, which will be proposed, generates combustion intensification processes. Due the combustion heat release into boiler furnace the fine solid particle of additive introduced in combustion air, becoming aerosols, decompose and give atoms of free oxygen. In air with additived aerosols will be develop two ionizations actions, having advantageous effects. Thus the released free oxygen, having negative charge determine the acceleration of approaching between $\mathrm{O}_{2}$ and hydrocarbons, resulting a faster combustion reaction with a flame shorter and closer. The molecular aerosols with negative charge act on the chains of hydrocarbons favoring their breaking off and reducing the necessary combustion energy. The ionization effect propagates in the whole combustion chamber. The optimal used additive is a mixing among different substances, as bichromates and chromates of potassium or sodium, derivates of nitric acid. etc., these mixtures being patented. The size of advantageous effects which can obtain by CWAA application, especially are function of characteristics and percentage content additive in electrolytic watery solution atomizing aerosols for furnace, the rate between additived air and total air for combustion, the quality of burned HFO, as well as the boiler operation time. For this reason is very difficult and expensive to obtain the optimal solution only direct by boiler industrial experiments. Thus the research and testing of CWAA, initially affected for optimization using graphologyc and thermographyc combustion simulators, appear as a very economical solution. 


\section{Heat exchange variation between droplet and combustion chamber wall.}

During the time of droplet existence of intermediate or heavy fuel oil droplet $\tau_{\mathrm{e}}=$ $\tau_{\mathrm{i}}+\tau_{\mathrm{v}}+\tau_{\mathrm{c}}$, the heat exchange by radiation between incandescent tubular furnace wall and the burning droplet, has an important variation. The new notations are: $\tau_{i}$ self-ignition delay time, $\tau_{v}$ combustion time of volatile matters and $\tau_{\mathrm{c}}$ combustion time of cenosphere. Indeed, the $P$ thermal power of radiation heat exchange between wall and burning droplet or vice versa, has a variation in $\tau$ time, which can be represented in a rectangular system of axes $P O \tau$, with $\tau$ for abscissa and $P$ on ordinate. For the $\tau_{\mathrm{i}}$ time (segment $\mathrm{Oa}$ on $\mathrm{O} \tau$ axe), the variation curve $\mathrm{P}=\mathrm{f}(\tau)$ shows a very slow decreasing. In the $\tau_{v}$ (segment ac), $\tau_{c}$ (segment ce) interval of times, aspect of heat exchange formulae become more complex due to the heat exchange between droplet flame or cenosphere variable in time, and the incandescent combustion chamber wall. After the appearance of droplet flame (point a on $\mathrm{O} \tau$ axe), in $\Delta \tau_{a b}$ time interval ( $b$ being the intersection between $P=f(\tau)$ curve and $O \tau$ axe), the flame receives heat from incandescent combustion chamber wall, but in $\Delta \tau_{b c}=\tau_{v}$ $\Delta \tau_{\mathrm{ab}}$ time interval the flame having a temperature larger as the incandescent wall, gives up heat to wall. The burning cenosphere, in $\Delta \tau_{c d}$ time gives up heat to wall and in $\Delta \tau_{\text {de }}=\tau_{c}-\Delta \tau_{c d}$ time receives heat from hot wall. A maximum value of the $\mathrm{P}=\mathrm{f}(\tau)$ curve for $\Delta \tau_{\text {de }}$ time interval, results especially due two contrary effects determined by: carbon combustion yielding heat of cenosphere and cenosphere incandescent surface decreasing in combustion process development together with the radiated heat. As a result of this phenomena, the infrared thermograms of the burning fuel oil droplet will give $T_{a}$ apparent temperatures, larger in intervals of times $\Delta \tau_{\mathrm{ab}}, \Delta \tau_{\mathrm{de}}$ and lower in intervals of times $\Delta \tau_{\mathrm{bc}}, \Delta \tau_{\mathrm{cd}}$, in comparison with the real possibilities of the tested fuel. Indeed, when the burning droplet receives heat from incandescent wall, a part of this heat is absorbs and reflects, thus increasing the radiated energy towards the detector of IR-Camera. When combustion chamber wall temperature is equal with environmental temperature $T_{e}$, ignition of droplet must be realized by a special igniter. But realizing the $T_{e}$ temperature for simulator combustion chamber is accomplished the main condition to obtain IR thermograms for real quality of experimented fuel oil.

\section{Thermographyc testing of burning droplet flame}

In fact, this testing generate a thermographyc method variant which represents especially a concretization of the combustion ITH development, founded on IRT analysis of the burning fuel oil droplet flame. The used simulator with an un-heated combustion chamber permits the burning at $T_{e}$ environmental air temperature of individual fuel oil droplets, with the initial mean diameter $d_{0}$ having temperature $T_{0}$. Was used an infrared camera (IRC) type ThermaCam PM 350 [2] operating in the wavelength infrared band $\Delta \lambda=3.4-5 \mu \mathrm{m}$, in order to obtain the IRT with thermal images. This IRT give the fields of apparent temperatures $T_{a}$ of burning droplet at a real - time $\tau$ of the combustion process development. The values of $T_{a}$ are function especially of: diameter $d_{0}$, time $\tau$ and fuel oil characteristics. These characteristics establish the combustion droplet fuel quality which determine the droplet combustion process development with droplet flame $T_{a}$ for his emissivity $\varepsilon$. From the IRT initial analysis has resulted that for a given fuel oil the apparent temperatures are greater when $d_{0}$ is greater and the $\tau$ time is nearer of value corresponding to the droplet flame maximum volume (VMFD), which is the reference value. Using an appropriate IRC, the mean real temperature $T_{r}$ corresponding to $T_{a}$, can significant characterize 
the fuel oil combustion process development. But $T_{r}$ temperature results when is know the emissivity $\varepsilon$ in direction of normal incidence of xAy plane of Fig.1, within the $\Delta \lambda$ band. The droplet symmetry center is specified by point $A$. Theory and practical experience show that in the IRT points of droplet flame, the emissivity $\varepsilon$ is variable in function of numerous parameters. These are especially: concentration in flame of soot fine particles (which is the most important parameter), content of $\mathrm{CO}_{2}$ and $\mathrm{H}_{2} \mathrm{O}$ gases which are released in combustion process, gaseous layer thickness and temperature of gases. But these parameters are variable in the time of droplet burning. For this reason it is impossible to determine with precision, even by special methods, the variable value of $\varepsilon$. In laminar diffusion flames, the soot forms on fuel rich side of the reaction droplet envelope formed by burning of yielded volatiles matters. Soot oxides as it diffuses into the hot reaction zone. Since the supply rate of soot is increased permanently not all of the soot can be oxidized. The soot that is not oxidized escapes from the tip of the flame. The height of the flame at which this occurs is called the sooting height. Provided the flame is over-ventilated, the sooting height is widely used as a measure of the propensity of a fuel to form soot [3]. This characteristic has been found to be remarkably sensitive to the fuel's molecular, that is depended by type of fuel oils. Many researches with laminar diffusions flames show that the sooting tendency of pure hydrocarbons rises in broadly the following order: alcohols, alkanes, branched alkanes, cycloalkanes, cycloalkenes, and aromatics. For this reason, the shooting hight value can give a new criterion of the classification according to the combustion quality, for gas oils. To obtain a small variation of $\varepsilon$ in normal direction at $x^{\prime} x$ axe for the interval of burning droplet liquid, with a reduce difference between $T_{a}$ and $T_{r}$, it is necessary to burn in ambient air relative large droplet releasing abundant soot by diffusion combustion and the environment giving a very low emissivity.. Thus, the released fine particles of soot are rich and spectral emissivity $\varepsilon(\lambda)$ varies slowly with wavelength $\lambda$, for some droplet flame zones, similar as for solid objects. In normal direction to xAy plane surface for the point $A$, where the released soot is larger, and the liquid droplet represent a background screen, the emissivity $\varepsilon$ for an industrial fuel oil in diffusion combustion, has a great value which can approach to blackbody emissivity. Apparent temperature $T_{A}$ for the point $A$ is computed according to radiation energy of the referent flame layer thickness with abundant soot, and the burning fuel oil droplet liquid. In direction from droplet towards the droplet flame ended, the emissivity decreases especially due soot concentration and gaseous layer thickness decrease, but increases with temperature diminution. Such as, if we admit $\varepsilon=0.9$, for which in IRT the temperature $T_{A}$ is determined, but in reality $\varepsilon$ decreases with 0.2 till a point of flame significant considered, in this point results $T_{r}=1.0648 T_{a}$. Indeed IRC can automatically realizes the correction for emissivity $\varepsilon$, but for the whole IRT. Thus for $\varepsilon_{1}$ the apparent temperature is $T_{a 1}$, and for $\varepsilon_{2}$ the apparent temperature $T_{a 2}=\left(\varepsilon_{1} / \varepsilon_{2}\right.$ )$^{0.25} T_{a 1}$, but the influence of $\varepsilon$ variation is much less important as temperature $T_{a}$ variation in the validity field of Stephan Boltzmann's law. For this reason, the analysis and comparison of $T_{a}$ temperature fields from IRT, according to $\varepsilon$ estimation give valuable qualitative information on diffusion combustion process development, very dependent on $T_{r}$ temperature. Also by use of the proposed method, analyzing IRT obtained by experiments performed in the same initial combustion conditions of droplets, for a tested fuel oil, and a standard fuel oil, new criteria of the fuel combustion quality determination, are established. Thus to characterize and compare, the gas oil combustion quality at VMFD, where defined criteria: $T_{m x}-$ average of flame apparent temperatures in normal direction on the $x x$ axe and $x A y$ plane, ${ }^{\circ} \mathrm{C} ; T_{t}$ - average of total flame apparent temperatures in normal direction on 
$x A y$ plane obtained by conversion of total radiation energy in $\Delta \lambda$ band, from the burning droplet, ${ }^{\circ} \mathrm{C} ; T_{A}$ - apparent temperature in normal direction on the $\mathrm{xAy}$ plane, for the point $A$. Also can be established secondary qualitative selection criteria in connection with the shape of curves for apparent temperature corresponding to $x x^{\prime}$ and yy' axes, namely $T_{\mathrm{ax}}=\mathrm{f}(\mathrm{x})$ and $T_{\mathrm{ay}}=\mathrm{F}(\mathrm{y})$. Experimental researches and testing were effected using the presented combustion simulator, and different types of gas oils, intermediate and heavy fuel oils, in the same initial conditions, characterized by: temperatures of environmental combustion air $T_{e}$ and fuel oil $T_{o}$; natural draft for combustion air feeding; cylindrical un-cooled combustion chamber; and initial mean diameter of droplet $d_{o}, \mathrm{~mm}$. It was necessary the realization of a special device for precise droplet calibration at diameter $d_{0}$ to obtain the same volume for every type of fuel oil. Also a special igniter was used. The range of $T_{a}$ measured temperature for the used IRC was limited in two distinctly intervals of temperature variation $\left(0-450{ }^{\circ} \mathrm{C}\right.$ and $450-2000{ }^{\circ} \mathrm{C}$ using an optical filter of the burning droplet radiations). During the majority of fuel oil tests, variation of above mentioned criteria, for $\varepsilon=1$, was: $T_{m x}$ $=295-357{ }^{\circ} \mathrm{C} ; T_{A}=387-447{ }^{\circ} \mathrm{C}$ and $T_{t}=263-293{ }^{\circ} \mathrm{C}$. The conclusion of numerous experiments and according theory shows that as for as the gas oil quality for combustion intensification is better, the criteria $T_{m x}, T_{A}$ and $T_{t}$ have larger values. For intermediate and heavy fuel oils, the droplet burning with flame is represented by $\tau_{v}$ and after this time following $\tau_{c}$, which also can characterizes the fuel quality. In addition, must be determined other specific characteristics concerning ignition, combustion and radiation CICR, by applying graphologyc method variant [1]. First of all, by efficient application of CWAA due the combustion intensification, on IRT appears an increase of $T_{a}$ in comparison with combustion without air additivation.

\section{Graphologyc method variant applied to CWAA and industrial applications}

This combustion testing method variant consist in the ignition and burning in an incandescent heated combustion chamber, under initial standard conditions, of an HFO calibrated droplet, whose radiated energy is received by a photocell, which transforms it into electrical signals in spectral band near infrared - visible (Fig.2). The experimentally obtained data are acquired, processed and stored in the memory of a computer, and then they are represented on computer display under the form of combustion oscillogram graphic. The standard conditions are mainly specified by: the geometry of the combustion chamber; the initial temperature $T_{i c}$ and pressure approximately equal to the atmospheric pressure inside the combustion chamber of simulator; the environmental temperature $T_{e}$ and temperature $T_{o}$ of fuel oil; system of supporting and inserting the droplet inside the hot combustion chamber; the air flow conditions around the droplet, mainly characterized by the value of air flow Reynolds number and the initial mean diameter $d_{o}$ of rigorous calibrated combusted droplet. The experimental researches and radiation-combustion-ignition characteristics $(\mathrm{RCIC})$ determination were carried out on a complex combustion simulator, fed with combustion air containing additived watery aerosols. These data result from interpretation of the combustion oscillograms of same droplets, experimentally obtained under the form of a curve represented in a rectangular system $10 \tau$. of coordinate axes The time $\tau$ variation is represented in the abscissa and the I radiation intensity variation of the burning droplet of HFO is represented in the ordinate. The radiation intensity is transformed into voltage for I or electric power, by means of a silicon photocell in band $\Delta \lambda=0.35-1.3$. The main RCIC of HFO combusted droplets with additived air by mixing with afferent aerosols are: self - ignition delay time $\tau_{\mathrm{i} a}$; combustion time of the volatile matters $\tau_{\mathrm{va}}$; cenosphere ignition delay time $\Delta \tau$ when 
exist; combustion time of cenosphere $\tau_{\mathrm{ca}}$; droplet flame radiated energy transformed by photocell into electric energy determined of the surface $S_{v a}$ between $I_{v a}=f_{a}(\tau)$ curve and $\mathrm{O} \tau$ axe, energy radiated by the burning cenosphere transformed by the photocell into electric energy determined of the surface $S_{c a}$ between $I_{c a}=F_{a}(\tau)$ curve and $\mathrm{O} \tau$ axe; maximum radiation intensities obtained at the combustion of volatile matters and cenosphere $I_{v a}^{m}, I_{c a}^{m}$.The surfaces $S_{c a}$ and $S_{v a}$ are:

$$
S_{c a}=\int_{0}^{\tau_{c a}-\Delta \tau} I_{c a} d \tau=\int_{0}^{\tau_{c a}-\Delta \tau} F_{a}(\tau) d \tau \text { and } S_{v a}=\int_{0}^{\tau_{v a}} I_{v a} d \tau=\int_{0}^{\tau_{v a}} f_{a}(\tau) d \tau
$$

For the combustion without additived air, the main RCIC are: $\tau_{i}, \tau_{v}, \tau_{c}, S_{v}$ and $S_{c}$ with the same meaning as $S_{c a}$ and $S_{v a}$.. Effecting numerous experiments, resulted that for an high efficient additive it is necessary to be simultaneously accomplish the conditions:

$$
\tau_{\mathrm{ia}}<\tau_{\mathrm{i}} ; \tau_{\mathrm{va}} \approx \tau_{\mathrm{v}} ; \tau_{\mathrm{ca}} \geq \tau_{\mathrm{c}} ; I_{v a}^{m}>I_{v}^{m} ; I_{c a}^{m}>I_{c}^{m} ; \mathrm{S}_{\mathrm{va}}>\mathrm{S}_{\mathrm{v}} ; \mathrm{S}_{\mathrm{ca}}>\mathrm{S}_{\mathrm{c}}
$$

$I_{v a}^{m}>I_{v}^{m}$ condition includes the above presented thermographyc conditions for droplet combustion intensification. When appear more solutions accomplishing conditions (2), the preferable solutions correspond to the maximum values for $I_{v a}^{m}$, $I_{c a}^{m}, \mathrm{~S}_{\mathrm{ca}}, \mathrm{S}_{\mathrm{va}}$ and the minimum values for $\tau_{\mathrm{ca}}, \tau_{\mathrm{ia}}$ times. These six magnitudes represent new scientifically criteria to select the variants of additivation, which will economical applied to the boiler, for the optimal solution establish. On the base of optimization of the quality and quantity of additive for aerosols, were effected industrial applications on different types of boilers using appropriate technologies as PIR and ACOM. The PIR technology conceived in Romania [4] was applied to relative small boilers for example with thermal power $5-12 \mathrm{MW}$ and to large boiler for example the energetic boiler of $530 \mathrm{MW}$ electric power.

The main advantageous effects: are: fuel savings, maintenance cost reduction and environmental pollution decrease. For the time $\tau_{\mathrm{va}}$ is applied flame thermographyc method variant for determination the influence of air additives on $T_{a}$.

\section{References}

[1] Ghia, V.V.; Efficient applications of a combustion testing graphologyc method for fuel oils. Proceedings of the 5th AITA, P, $41-48$, Venezia (1999)

[2] Ghia,V.V., Dumitraşcu C. N.; Method using infrared thermography for combustion testing of fuel oil. Rev. Roum. Sci. Techn.- Électrotech. et Énerg., Tome 47, no. 2, P, 219-229, Bucharest (2002) 
[3] Landommatos N. and others,; The effect of aromatic hydrocarbons on soot formation in laminar diffusion flames and a diesel engine. Journal of the Institute of Energy, Sept. 70, P, 84-94, London (1997)

[4] Radulescu, M.,; Technologies for improving combustion processes of heavy fuel oils (part II) Rev. Energetica, serial A, no. 7, P, 297-308, Bucharest (1999)

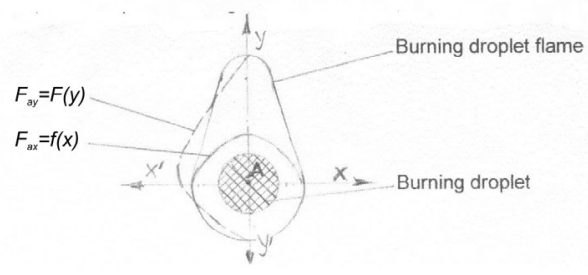

Fig.1 - Flame infrared thermogram, schematically presented of a superior gas oil, at the droplet flame maximum volume.

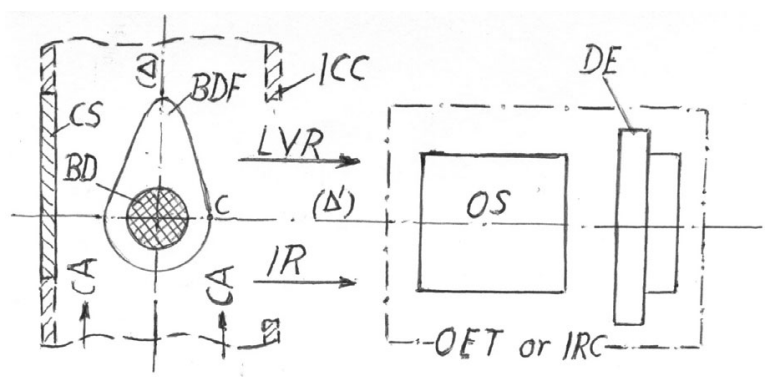

Fig. 2 - Conversion system of the burning droplet radiation into electrical signals. (BDF - burning droplet flame; ICC - incandescent combustion chamber; LVR - light visible radiation; OET - optical electronic transducer; IRC - infrared camera; IR infrared radiation; OS - optical system; DE - detector; CA - combustion air; CS cooled screen;

$B D$ - burning droplet; - - -for ICC of simulator) 